\title{
COLLABORATION \& DESIGN THINKING: A TRANSDISCIPLINARY APPROACH TO REDEFINING THE NEXT NORMAL AND CREATING RESILIENT ECOSYSTEMS
}

\author{
Montressa L. Washington, Shenandoah University, Winchester, VA, U.S.A. \\ Jennifer R. Madden, Carthage College, Kenosha, WI, U.S.A.
}

dx.doi.org/10.18374/RBR-20-1.6

\begin{abstract}
Collaboration is recognized as a viable strategy for addressing uncertain, complex, and wicked social problems. Design thinking has emerged as the premier organizational path to innovation and high-performance collaboration. Design thinking is useful in tackling complex problems that are ill-defined or unknown and by reframing the problem in human-centric ways this hands-on approach to problem solving makes way for innovative solutions. There are similarities between designers and collaborators, we conjecture that adopting design strategies is an important foundation for assembling successful collaborations tasked with solving problems quickly arising in this unprecedented time of disruption and monumental change. These collaborations of transdisciplinary teams cross many disciplinary boundaries to create a holistic approach using the power of design thinking coupled with robust collaborative technology to design bold, inclusive, and sustainable solutions. In addition, these collaborations are supported by digital technologies that enable capturing, analyzing and sharing data that is transparent and transformational. We propose a conceptual model of the moderating effect of design thinking on the collaboration variables (leadership, power, experience) affecting successful collaboration design and redesign contributing to the creation of resilient ecosystems
\end{abstract}

Keywords: Designing collaborations, design, design thinking, cross-sector collaboration, transdisciplinary teams, public-private partnerships, power, leadership, experience. 